Tesis. Año 14, 13(16), 2020, 77-96

\title{
Vanguardia política y vanguardia artística en las revistas de Vicente Huidobro. EI discurso polémico en Ombligo y Vital (1934, 1935)
}

\author{
Rocío Ibarlucía ${ }^{1}$ \\ rocioibarlucia@gmail.com
}

\section{Resumen}

Las revistas Ombligo y Vital, dirigidas por Vicente Huidobro entre 1934 y 1935, presentan un repertorio de discursos en torno de la Revolución Rusa, el movimiento obrero en EE. UU. y las políticas conservadoras chilenas, gracias al cual es posible redefinir la figura del poeta, generalmente encasillada en la vertiente artística de las vanguardias latinoamericanas. El artículo analiza las polémicas entabladas entre Huidobro e intelectuales chilenos, para lo cual apelamos a nociones provenientes de la teoría de la argumentación propuesta por Perelman (1989). Observamos una ridiculización de la argumentación política mediante comentarios irónicos que refuerzan la denuncia a las doctrinas de derecha. Estos órganos de difusión, entonces construyen una escritura sostenida en la ironía a fin de disputar un lugar privilegiado en el campo literario local, lo que obliga al propio Huidobro a revisar su proyecto creador y, en consecuencia, a restablecer los préstamos entre vanguardia artística y vanguardia política.

Palabras clave: Huidobro, vanguardias latinoamericanas, revistas literarias, discurso polémico, ironía.

\section{Abstract}

The journals Ombligo and Vital led by Vicente Huidobro between 1934 and 1935 present a repertoire of discourses of the Russian Revolution, the workers' movement in the US and Chilean conservative policies that lead to redefine its figure of poet, usually typecast in the artistic side of the Latin American vanguards. This article evaluates the debates between Huidobro and other Chilean intellectuals, poets, literary critics and political leaders gathered in these publications. After analyzing the controversial speech from argumentation theory (Perelman, 1989), we observe a ridicule of rhetorical argumentation policy through ironic commentaries that never fail to denounce the doctrines of right. These organs of diffusion, then build a sustained write in the irony in order to contest a privileged place in the literary field, forcing the own Huidobro to review his project and, consequently, to restore the loans between aesthetics and political vanguards.

Key words: Huidobro, latinamerican vanguards, literary journals, polemics, irony. 


\section{Vanguardia política y vanguardia artística en las revistas de Vicente Huidobro. EI discurso polémico en Ombligo y Vital (1934, 1935)}

\section{Introducción}

Durante la década del 30, a raíz de una serie de profundas transformaciones sociales y políticas, se producen fervorosas discusiones dentro del campo intelectual chileno respecto del posicionamiento ideológico que debe tomarse frente a la Revolución Rusa, los fascismos europeos, las huelgas en Norteamérica o las políticas de derecha en América del Sur. Del mismo modo, se pone en duda el proyecto literario acorde a nuestro continente en este contexto de conflictos sociales. Las revistas dirigidas por Vicente Huidobro entre 1934 y 1935 intervienen en estos debates mediante una actitud combativa en contra de los conservadurismos políticos y artísticos. Los textos incluidos en Ombligo y Vital se oponen a la prensa funcional al gobierno chileno; en especial, a La Nación y La Opinión de Santiago de Chile, y a sus principales defensores, como Ricardo Boizard. ${ }^{2}$ Asimismo, desprecian a los dirigentes políticos anticomunistas, como Rafael Luis Gumucio y Arturo Olavarría, y exponen su aversión a los críticos literarios de la escuela tradicionalista, como Hernán Díaz Arrieta. Estas acusaciones se efectúan a través de un discurso polémico, caracterizado por la apropiación de retóricas estereotipadas de la argumentación política y académica, que se resignifican al emplear juegos humorísticos para denunciar las doctrinas de derecha. Por otro lado, Vicente Huidobro se enfrenta a los poetas chilenos Tomás Lagos, Diego Muñoz y Luis Enrique Délano, aunque la polémica que más ha trascendido es sin dudas la mantenida con Pablo Neruda, a quien le dedica un número completo de Vital para imputarlo por supuestos plagios. La invectiva contra el autor de Residencia en la tierra se construye a través de una belicosidad discursiva construida mediante el empleo de un léxico querellante, al punto de proclamar el acta de defunción de su rival.

Por lo tanto, este trabajo propone examinar a través de un análisis textual-discursivo los debates poéticos y políticos - con sus correspondientes imbricaciones- entre Vicente Huidobro y otros intelectuales chilenos reunidos en las revistas Ombligo y Vital, tomando en consideración asimismo vínculos con 
su obra poética precedente. De este modo, los primeros dos órganos de difusión construyen un discurso polémico sostenido en la ironía a fin de conseguir un lugar privilegiado en la estructura del campo literario local. Las acusaciones contra Huidobro lo obligan a redefinir su proyecto creador y, en consecuencia, a restablecer los préstamos entre vanguardia artística y vanguardia política.

\section{Argumentación polémica: cruces entre retórica y política}

Para el análisis de la polémica en las revistas de Huidobro, resultan pertinentes los estudios sobre la retórica y sus intersecciones con la política, dado que el director de estas publicaciones entabla disputas tanto estéticas como éticas. Ya desde su Política, Aristóteles define la retórica en términos del arte de la persuasión por medio del lenguaje, instrumento necesario para ejercer la ciudadanía. El filólogo español Antonio López Eire, en su trabajo sobre la obra del estagirita, destaca el carácter indisociable entre la forma y la finalidad en un discurso persuasivo; por ello, para lograr los propósitos buscados, el estilo ha de ser claro, ordenado, cohesivo, sin vulgaridades ni ofuscamientos, simultáneamente simple y complejo (López Eire, 2000). A partir de estas premisas-características del discurso polémico, proponemos indagar las vinculaciones entre las formas de argumentar de estas revistas y los objetivos perseguidos. El discurso polémico de Ombligo y Vital revela su desvío respecto de esas premisas aristotélicas sobre la forma, puesto que propone la exploración de tretas vanguardistas destinadas a destruir la lógica lineal. Si bien la forma en estos textos no construye la organicidad sino la destrucción del orden, igualmente el estilo "ombliguista" y "vitalista" se adapta a una de sus finalidades: reivindicar y defender su arte vanguardista, caracterizado por desarticular el lenguaje y crear un universo no referencial, como promueven manifiestos y poemas creacionistas del propio Huidobro.

Revisitar estas teorizaciones sobre la retórica y la política colabora en la evaluación del discurso polémico de Huidobro, ya que en sus textos es relevante el efecto buscado en sus destinatarios y, en especial, en el campo literario chileno y de lengua española. De acuerdo con López Eire:

Todo acto de habla (y el discurso retórico lo es) implica una alocución a un destinatario, de manera que la Retórica es el arte de persuadir mediante un acto de habla dirigido a un destinatario del mensaje físicamente distinto del locutor, pero capaz él mismo de ser interlocutor, lo que significa que uno y otro comparten una misma "competencia comunicativa". (2000, p. 99)

Por ende, examinaremos las inferencias pragmáticas propias de un acto de persuasión, en tanto las acusaciones elaboradas por estas revistas no son directas, sino que están plasmadas de enunciados irónicos y burlones. Al mismo 
tiempo, en la cita anterior se menciona que los interlocutores deben tener la misma "competencia comunicativa", es decir, la coincidencia de conocimientos lingüísticos y socioculturales adquiridos a través de los intercambios dentro de una comunidad política. Con respecto a ello, Huidobro tiende a exhibir sus competencias comunicativas con el fin de justificar su pertenencia autorizada al campo intelectual del que se busca excluirlo. Por medio de sus estrategias discursivas pone a funcionar sus conocimientos sobre los códigos implementados por sus colegas poetas a fin de corroborar su legitimidad.

Desde la perspectiva de la "nueva retórica", Charles Perelman, en Tratado de la argumentación, establece una diferenciación entre la retórica y la filosofía, al presentar, cada una, metas diferentes:

Persuadir y convencer son las dos finalidades de la argumentación que corresponden a la retórica y la filosofía. Persuasión connota la consecución de un resultado práctico, la adopción de una actitud determinada o su puesta en práctica en la acción. El convencimiento no trasciende la esfera mental. (1989, p. 16)

Como la argumentación retórica se vincula con la producción de una acción consecuente y no una reflexión abstracta, nos preguntamos por el objeto de las persuasiones de Vicente Huidobro, por la identidad de sus destinatarios y, sobre todo, por sus finalidades. En principio, sostenemos que intenta defender su poesía ante las acusaciones del círculo literario local para así trascender y participar activamente en la construcción de una poesía revolucionaria en términos estéticos y éticos.

\section{Ironía y denuncia en las polémicas de Ombligo y Vital}

$\mathrm{E}$ l inventario de temas propuestos por las revistas Ombligo/Vital, que abarcan desde la Revolución Rusa, el movimiento obrero en Estados Unidos hasta la política inmigratoria y otros proyectos de la nación chilena de los años 30, pone de manifiesto los cruces entre poesía vanguardista y denuncia política. Asimismo, sus textos y paratextos exponen una actitud "activista", rasgo propio de la vanguardia según Poggioli, en tanto evidencian una "oposición contra algo o contra alguien" (1964, p. 40). Los discursos contenidos en estas publicaciones, por ende, se constituyen a partir de enfrentamientos permanentes contra distintos enemigos. Cabe recuperar en esta instancia que el discurso político, por ser una lucha discursiva entre enunciadores (Verón, 1987), tiende a dialogar con distintos tipos de destinatarios: el positivo (prodestinatario), el negativo (contradestinatario) y el "tercer hombre" (paradestinatario). ${ }^{3} \mathrm{~A}$ partir de estas categorías de Eliseo Verón, la investigadora argentina María Marta García Negroni (2016) propone complejizar el estudio del contradestinatario, al considerar que se puede identificar en el campo discursivo de lo político "destina- 
tarios negativos" indirectos o encubiertos. A la luz del enfoque dialógico de la argumentación y de la polifonía enunciativa (Bajtín, 1982; Ducrot, 1984) —es decir aquellas teorías que consideran la superposición de discursos y puntos de vista en la constitución del sentido del enunciado- la autora sostiene que en muchas ocasiones los discursos políticos incorporan el discurso ajeno (opuesto al propio) de manera indirecta. Algunas formas de apropiarse de otros enunciados son, en términos de García Negroni, las negaciones metadiscursivas, las afirmaciones enfáticas refutativas o las incorporaciones burlonas e irónicas. Los discursos de estas revistas incluyen y reformulan enunciados ajenos a fin de descalificarlos mediante la ironía, como veremos a continuación.

En la portada de Ombligo, se incluye el manifiesto de la revista, donde se enumeran definiciones de este grupo: "Ombligo reacciona contra lo genial, lo poético y lo grandioso por eso no se llama 'Atenas', ni 'Minerva', ni 'Siglo XX', ni 'Selecta”' (Huidobro, 2012c, p. 21). ${ }^{4}$ Su enfrentamiento, entonces, se efectúa en contra del arte tradicional, clásico y burgués, por su carácter sublime y elitista, así como también desacredita otras estéticas contemporáneas autodenominadas "modernas", según puede observarse en "Ombligo detesta el maquinismo futurista y las locomotoras que huelen a patas de Marinetti" (p. 21). ${ }^{5}$ Por un lado, aboga por un cambio estético y social al ir en busca de nuevas expresiones y órdenes políticos, por otro lado, destruye la tradición precedente a través de un gesto parricida, en especial por intentar romper con la lógica del pensamiento occidental: "Ombligo cree en la cuadratura del círculo" (p. 21). ${ }^{6}$ De allí, el uso reiterado de la paradoja, un procedimiento que es una provocación para la lógica, como puede notarse en la contradicción: "Ombligo no cree en lo ilógico. / Ombligo no cree en lo lógico” (p. 21). El texto programático finaliza con la aseveración "Ombligo sólo cree en Ombligo. / Y por lo tanto en la revolución mundial” (p. 21), socavando la lógica causa-efecto. Los miembros de esta publicación periódica plantean pues su propio credo poético basado en la creación de un universo emancipado del mundo exterior, aunque eso no implica la falta de compromiso político. Por el contrario, su apuesta reside en divulgar una escritura novedosa y rebelde para producir cambios en el funcionamiento social a nivel nacional y más allá de las fronteras del país. En definitiva, el manifiesto de la revista Ombligo continúa la propuesta vanguardista del creacionismo sin dejar de imbricarla con una vanguardia política, al concebir literatura y revolución como conceptos interdependientes.

“Viva la libertad! ¡Viva la inteligencia!” es uno de los textos en prosa incluidos en la revista Ombligo que evidencia desde el título el empleo de la ironía. Cabe aclarar que comprendemos este concepto desde la perspectiva de la teoría de la argumentación (Perelman \& Olbrechts-Tyteca, 1989), lo cual implica considerarlo no como un recurso, sino como una forma de argumentar, que utiliza un vasto número de procedimientos estilísticos, gráficos y discursivos. Desde la primera oración, "De orden de la autoridad, a partir de mañana, todo 
ciudadano debe ser sordo, ciego y mudo" (p. 23), se introduce una notoria crítica a las autoridades políticas llevada a cabo por medio de una antífrasis; esto es, mostrar una idea opuesta a la que se quiere afirmar. También el uso de los signos exclamativos en "iAy de aquel que vea, que oiga, o que hable!” (p. 23) ofrece una clave para interpretarlo con sentido irónico. Ese distanciamiento crítico se extrema aún más en el final de este apartado: "Todo el que se muera de hambre y de miseria será considerado un subversivo y su cadáver será quemado ante los verdaderos patriotas dignos de ver el hermoso espectáculo" (p. 23). La generalización expuesta en el sustantivo "todo", el grado de aseveración brindado por los verbos en futuro simple y las elecciones semánticas de la pobreza extrema señalan la representación irónica del discurso ajeno, del que se distancia de forma cada vez más ostensible al extremar sus afirmaciones hiperbólicamente.

Acto seguido, se inscriben dos secuencias exhortativas que tienen la misma estructura sintáctica:

Es obligatorio gritar ¡Viva Gamucio! ¡Viva Boizard! ¡Viva Olavarría! Los amigos del orden y de la inteligencia que lancen estos gritos, tendrán un día su estatua y una torta del mejor turrón.

Es prohibido gritar ¡Viva André Gide! ¡Viva Barbusse! ¡Viva Einstein! ¡Viva Stalin! Los disolventes que lancen estos gritos serán convertidos en charqui. (23)

Tal paralelismo crea una nueva antífrasis al proponer dos ideas opuestas que desean afirmar exactamente lo contrario. Además, la tematización del verbo conjugado en tercera persona del singular en presente del indicativo introduce una definición, procedimiento propio del discurso argumentativo, aunque en este caso empleado para dar órdenes absurdas. Mientras que en la primera oración se enuncian figuras chilenas de la política y el periodismo asociadas al campo de la derecha ultraconservadora y anticomunista, los segundos se agrupan por su defensa del comunismo. ${ }^{7}$ En estas afirmaciones irrumpe un contraste con respecto al estilo reinante, puesto que incluye una alusión de orden alimentaria que resulta inesperada. Un acto solemne y oficial, como lo es erigir una estatua, sufre una degradación al hacerlo caer al mismo nivel que algo tan trivial como una torta de turrón. La argumentación construida a lo largo de este texto, por ende, dialoga con los discursos provenientes de la ideología de derecha, que por presentarse exagerados, resulta evidente su rechazo y desacreditación.

La negación es otra técnica empleada para producir ironía, como se refuerza anafóricamente en el siguiente fragmento: "No vayan a creer ustedes que las huelgas de Estados Unidos son huelgas. No, señores, son romerías. / No crean ustedes que el socialismo se está edificando en Rusia. Lo que se edifica en Rusia es el capitalismo. Por eso los capitalistas aplauden y los obreros rabian" (p. 23). El uso del estilo indirecto libre resulta funcional para la argumentación política 
de este texto, en tanto le permite recuperar y reformular las palabras ajenas desde un distanciamiento crítico e irónico. El uso insistente de la negación pone en evidencia la separación entre el enunciado del otro y el propio. Ducrot (2004) señala que la negación es una forma de dialogismo, utilizada en este caso para rechazar y ridiculizar de forma irónica el discurso citado: reduce de manera irreverente y desacralizadora las manifestaciones obreras estadounidense tras la crisis financiera del 29 a la condición de peregrinaciones religiosas, al igual que la situación sociopolítica de Rusia, que es redefinida por medio de una inversión de los lugares comunes sobre dicho territorio. Lejos de encubrir este posicionamiento, se pone en primer plano las estrategias discursivas realizadas por los sectores hegemónicos en los medios periodísticos y en los discursos de los representantes políticos, quienes buscan desmentir los hechos y acciones asociadas al socialismo ruso y las movilizaciones sindicales norteamericanas.

La crítica irónica se acrecienta hacia el final del texto cuando esa refutación crece por hiperbolización: "No crean ustedes que Rusia es la sexta parte de la tierra. Mentira de los canallas disolventes. Rusia es la sexta parte de una millonésima de un cuadrante del meridiano lunar" (p. 23). Este fragmento exhibe la falsedad de los argumentos de esta clase dirigente que combate contra el comunismo y las luchas de izquierda. Por tanto, la estrategia discursiva consiste en contrahacer el estilo del discurso de los "otros". Si bien no se trata de citas directas, se ridiculizan las ideas fascistas al adulterar datos obvios como declarar que Rusia está en la luna. Finalmente, el carácter absurdo de sus razonamientos es enfatizado al desmentir obstinadamente las adquisiciones sociales de la Revolución Rusa: "Sepan ustedes que en Rusia todo el mundo se muere de hambre. En Rusia no hay habitantes. Todos se murieron de miseria. No hay ni un solo habitante. Algunos enemigos del orden quieren hacernos creer lo contrario. Sabremos castigar a estos rotos sublevados" (p. 23). Otra vez, la reiteración de las negaciones y el uso de la generalización acentúan el carácter exagerado y, por tanto, evidencian la caricaturización de la ideología derechista.

En la publicación número 1 de la revista Vital se incluye un texto breve titulado "Inmigración", que por medio de la ironía y la burla denuncia las políticas inmigratorias efectuadas en Chile y la región. La diferencia con el discurso anterior radica en que, en lugar de apropiarse del discurso conservador en primera persona, se produce un distanciamiento entre el pensamiento totalitario y el progresista al segregar entre los que están de un lado y los del otro. Sin embargo, ello no quiere decir que no se incluyan formulaciones propias de la discursividad conservadora. Mediante la pregunta retórica “¿Quiere ser Ud. el más gran [sic] gobernante de Chile?” (p. 27), banaliza una candidatura política al hacerla ingresar en un ámbito nuevo como es el comercial. La ironía cobra aún más relevancia en la aclaración parentética "(Hablando en sentido burgués)" (p. 27), donde se esclarece que se trata de un juicio asociado a las esferas acomodadas. La respuesta es traer inmigración, "mucha inmigración" 
(p. 27), propuesta que debe defender a través de la anticipación a las posibles argumentaciones adversas: "Los que le arguyan que no se puede traer más gente a un país en que hay cesantía son unos tontos" (p. 27), recurriendo a sus explicaciones para contrarrestar dichas premisas simples y directas como un juicio de valor descalificativo.

Para profundizar sobre la validez del ingreso de inmigrantes, introduce como estrategia una cita de autoridad de Mussolini: "Si no me cree a mí, créale a uno de su lado, a Mussolini, que dice en un artículo publicado en Marzo de este año 1934 en 'Popolo d'Italia', las siguientes verdades indiscutibles" (p. 27). Primero, homologa la ideología de Mussolini con la del gobierno chileno al considerarlo "de su lado". Luego, se apropia de lo dicho por el dictador italiano aunque, al situarlo en un territorio diferente, se distancia de él para producir un efecto cómico; en otras palabras, cita este texto con el objeto de deformarlo. Así, lo referido se invierte puesto que transforma una opinión en "verdad indiscutible". Tras dicha cita de autoridad, se enuncia "Sin necesidad del señor Mussolini, esto lo sabe hoy toda persona con dos dedos de frente" (p. 27). Por tanto, el reciente alegato que ha servido como justificación de lo afirmado, ahora sufre una deflación, puesto que reduce las palabras del líder del fascismo italiano a la de una persona con mero sentido común, a través de una expresión coloquial e informal. Nuevamente, su argumentación política se constituye mediante una enunciación indirecta que rechaza los razonamientos de la derecha, distanciamiento identificable por hacer manifiesto el sinsentido de sus ideas y sus formas. La cita se torna objeto de crítica al exhibir que se trata de un discurso estereotipado y automatizado de la comunidad política conservadora. Por otro lado, es pertinente resaltar que la ironía empleada hasta el momento no es una mera técnica cómica, sino una profunda crítica a la forma de pensar y actuar de los fascismos europeos y las políticas chilenas. El texto tiene como finalidad política revisar las bases ideológicas de dichos gobiernos y proponer desde el arte su socavamiento y reformulación.

La segunda cita de autoridad refiere al "gran estadista argentino Alberdi": "El gobernante sudamericano que no duplica la población de su país cada cinco años hasta llegar a su término medio lógico, debe ser considerado un inepto" (p. 27), ante lo que responde: "Chile será un país miserable y ridículo hasta que no tenga veinte millones de habitantes" (p. 27). En este caso, incluye una cita textual, pero en lugar de manifestar su enfrentamiento de forma directa, lo hace una vez más por medio de la crítica irónica — puesta en primer plano por la hipérbole de la decadencia y la imposibilidad de crecimiento económico-, así como vuelve a enfatizar la carencia de "orden y progreso" por medio de la negatividad: "Nada puede prosperar, ni la industria, ni la agricultura, ni las artes, ni la ciencia, en país despoblado” (p. 27). La premisa hiperbólica se intensifica al ordenar que el gobierno tiene que llevar a cabo un plan para "traer un millón de emigrantes por año” (p. 27). Nuevamente se despliegan clichés, fra- 
ses cristalizadas, retóricas estereotipadas tomadas de los enunciados del campo intelectual conservador y las esferas dominantes, todos ellos incorporados de forma burlona.

Gracias al examen de ciertos textos incluidos en las revistas dirigidas por Vicente Huidobro en 1933, hemos observado una forma de argumentar que construye una crítica irónica al campo intelectual chileno, así como una burla despiadada contra los regímenes totalitarios. Se toman retóricas estereotipadas de la argumentación política y académica para resignificarlas desde el humor y la denuncia a las doctrinas conservadoras y fascistas tanto en Europa como en Latinoamérica. De este modo, se pone en evidencia una transmutación paulatina de su arte hacia uno más comprometido sin abandonar su estética vanguardista, signada por la provocación y la ruptura. Así, exhibe un nuevo posicionamiento poético que lo lleva a demarcar una renovada figura de autor comprometida que desobedece reglas para rivalizar contra la cultura hegemónica y reformular los discursos instalados y obsoletos.

\section{La polémica entre Neruda y Huidobro en Vital 1}

La resonante y prolongada enemistad entre Pablo Neruda y Vicente Huidobro ha suscitado la producción de numerosos artículos periodísticos, cartas, conferencias y comentarios de escritores chilenos - Pablo de Rokha, Volodia Teitelboim, Rosamel del Valle, Edgardo Anguita- y extranjeros - Tristan Tzara, Alejo Carpentier, César Vallejo, Juan Larrea, por nombrar algunos-, así como una vasta publicación de estudios académicos (de Costa, 1978; Molina, 1995; Morelli, 2007; Sanhueza, 2004; Zerán, 2011). Asimismo, la gran cantidad de textos polémicos escritos por los dos poetas y la duración de la disputa desde los años 30 hasta los 70, incluso después de la muerte de Huidobro ocurrida en 1948, ha dificultado el esclarecimiento de las causas de esta querella literaria. Milena Rodríguez Gutiérrez define el enfrentamiento como "una polémica transatlántica, relevante para la poesía y para los poetas de lengua española" (2008, p. 187), por tratarse de dos escritores que han vivido en España y Francia y que, a su vez, han mantenido estrechos lazos intelectuales con reconocidas figuras de la literatura europea. De hecho, la conflagración ha perjudicado al autor de Altazor, en tanto ha sido una figura menos conocida en Europa y, en menor medida, en Latinoamérica. Por otro lado, según la autora, no es una simple polémica sino un "desencuentro estético, personal y político, que duró prácticamente toda la vida de ambos” (2008, p. 185).

Se trata de un desencuentro estético porque defienden dos universos poéticos antagónicos e incompatibles: la poesía impura y el creacionismo. Por un lado, Neruda en el manifiesto "Sobre una poesía sin pureza" (1935) propone una lírica que, en oposición a la poesía pura de Juan Ramón Jiménez, no debe referir solamente a lo bello, lo sublime, lo sagrado, sino que debe "mancharse 
del sudor del trabajo”. Sus textos, entonces, reúnen diferentes órdenes de la vida cotidiana a través de enumeraciones que yuxtaponen lo alto y lo bajo: "Así sea la poesía que buscamos, gastada como por un ácido por los deberes de la mano, penetrada por el sudor y el humo, oliente a orina y a azucena salpicada por las diversas profesiones que se ejercen dentro y fuera de la ley" (Neruda, 1975, p. 5). Los participios, por su parte, forjan su alejamiento del torremarfilismo modernista al evitar una posición de privilegio para, en cambio, involucrarse con el mundo material del trabajo obrero. La tarea del poeta, en esta perspectiva, se equipara a la labor de cualquier trabajador. En cambio, Vicente Huidobro formula una poesía apartada de la experiencia diaria, de la mímesis y la observación. En su manifiesto Non Serviam (1914), el poeta se proclama amo y no esclavo de la Madre Naturaleza, lo que pone de manifiesto que ya no se busca imitar el mundo sino crear una realidad alternativa. En consonancia, el poemario El espejo de agua incluye una nueva definición en "Arte poética" (1916), cuyo verso final - "El poeta es un pequeño Dios" (Huidobro, 2012b, p. 21) - hace hincapié en la imaginación y la invención frente a la mímesis. ${ }^{8}$ Además, "Por qué cantáis la rosa, joh Poetas! / Hacedla florecer en el poema” (2012b, p. 21) condensa su propuesta que consiste en homologar la fundación de un lenguaje con la fundación de un mundo a través del quiebre de la relación preestablecida y arbitraria entre la palabra y la cosa, entre el significado y el significante. Su obra magna, Altazor o el viaje en paracaídas (1931), lleva al extremo esos desajustes lingüísticos al proponer una desarticulación (Ostrov, 2006) progresiva del lenguaje que culmina en el nivel del puro significante. Frente a la lógica realista, objetivista y descriptiva, la obra poética de Huidobro pone en tensión el vínculo con lo real por medio de la inclusión de imágenes creacionistas, la yuxtaposición de elementos irreconciliables, el montaje y un discurso de la fragmentación. La desarticulación del lenguaje se torna indisociable de la desintegración paulatina del sujeto, la razón y la poesía (de Costa, 1984; Rojas, 1999; Ostrov, 2006). En conclusión, la poesía impura y el creacionismo parten de dos miradas estéticas irreconciliables al proponer la primera una literatura de carácter vital ligada a la realidad material y la segunda, la autonomía del objeto artístico.

Tal divergencia artística se enlaza con un "desencuentro personal", que se debe a una disputa por el reconocimiento nacional e internacional de su figura de poeta e intelectual. Según César Antonio Molina, Neruda está "obsesionado por ser el poeta nacional no sólo de su país, sino de todo un continente, como Whitman ya lo fuera del norte. Huidobro no menos preocupado por ser reconocido como el más internacional, el más original y el primero en casi todo" (1993, p. 137). Por ello, el autor de Residencia en la tierra emplea una serie de estrategias discursivas y mediáticas, al igual que lo hace Huidobro, para divulgar la carencia de compromiso social atribuida a la poesía creacionista y también en la vida de su fundador: 
$[\mathrm{H}]$ ay literatos de siniestra cara, ladrones verdes, payasos de París (...) fabricando pequeños 'plagios', disfrazados de comunistas náufragos y fecales (...) mientras el mundo cae y nace, sólo el odio y la envidia crece en sus uñas, y se preocupan de denunciar, de mancillar, los hediondos, mientras Alberti lucha, González Tuñón lucha, Aragón lucha (Neruda, 1975, pp. 377-378).

Al mismo tiempo, Neruda abre por medio de esta acusación el "desencuentro político", dado que presenta a Huidobro como un desentendido de las luchas sociales y las denuncias de sus coetáneos. Ahora bien, como sostiene Molina, "ambos eran también militantes comunistas, lo que provocó la recriminación por parte de Tzara y otros escritores que veían en peligro la unidad de los intelectuales ante la defensa de la República Española” (1993, p. 137). Resulta pertinente aclarar que Huidobro ha sido militante del partido desde 1931 hasta 1940 - a causa del pacto germano-soviético- mientras que Neruda comienza su militancia desde 1945 hasta su muerte, como aclara Rodríguez Gutiérrez.' Por otro lado, Jitrik en "Las dos tentaciones de la vanguardia" (1995) parte de dos anécdotas de los poetas chilenos para señalar que la vanguardia artística de Huidobro se caracteriza por ser un acto individualista, carente de dimensión política, proveniente de una ideología del pequeño burgués, mientras que la vanguardia política de Neruda consiste en un acto colectivo, con sentido histórico, toques criollos y que cumple una función social. Así, contrapone un arte autorreferencial frente a un arte vital. Esta visión, tal como alerta el propio Jitrik, resulta esquemática dado que tales tendencias se imbrican en la práctica escritural y en las acciones dentro del campo cultural. El mismo Huidobro luchó en la Guerra Civil Española, fue capitán del Ejército Francés de Liberación y entró en Berlín con las tropas aliadas (Rodríguez Gutiérrez, 2008, pp. 198199). Por ende, resulta necesario revisitar su escritura a fin de problematizar la figura de autor de Huidobro, habitualmente encasillado en la vanguardia artística y opuesta a la vanguardia política.

El punto de partida de esta famosa rivalidad no puede señalarse con precisión, aunque ciertos estudiosos, como René de Costa (1978), afirman que la publicación del texto "El affaire Neruda-Tagore" en la revista Pro (noviembre 1934) produce un quiebre en la relación Neruda-Huidobro. Dicho texto, donde se acusa a Neruda de haber plagiado un poema de Tagore, no fue escrito por el fundador del creacionismo sino por Volodia Teitelboim, figura cercana a Huidobro, quien colabora en las dos revistas de nuestro corpus. Sin embargo, la denuncia es republicada en la portada del segundo número de Vital en enero de 1935 tal como aparece en Pro, con la transcripción de los dos poemas en cuestión: "Poema 30" de Tagore y "Poema 16" de Neruda. El artículo dialoga con la nota al pie de página de Vital — no por ello menos visible-: "Quieren pelea, ahora van a saber lo que es pelea" (p. 29), que introduce la querella desde un lenguaje vehemente y combativo. Desde esta frase, la disputa se define en la 
revista huidobriana como una "pelea", lo que implica el enfrentamiento de dos fuerzas opuestas que tiene como fin destruir al enemigo. La primera estrategia empleada para ganar la disputa consiste en una breve descripción sobre la copia realizada por Neruda. Se destaca, en principio, el impacto que ha tenido en el ámbito literario, que es denominado como "circulillos de Los Compinches" (p. 30), sufijo que descalifica y disminuye el prestigio de los colegas poetas, quienes manifiestan una "Gran indignación, furia (uterina)" (p. 30). La aclaración parentética desliza una nueva burla de tintes misóginos hacia tal circuito poético al caracterizar su cólera con una actitud ninfomaníaca. La semántica del galicismo affaire, palabra incluida en el título, introduce un juego de palabras al colocar esta rencilla literaria entre un conflicto escandaloso y una aventura amorosa. Luego, se detiene en el propósito de esa furia por medio de preguntas que buscan averiguar el destinatario de la indignación. Estos interrogantes no esperan ser respondidos, sino exhibir su opinión acerca de la mediocridad de los dos poemas: “¿Contra Tagore por haber escrito diez años antes un poema bastante tonto?” (p. 30, énfasis nuestro).

Inmediatamente después, la revista Vital hace hincapié en el cuestionamiento que Neruda y su círculo realizan contra Huidobro, quien no forma parte de las acusaciones del plagio Neruda-Tagore, según sus declaraciones. Ante tal inculpación, se conjeturan las posibles causas de la animadversión de Neruda hacia Huidobro, como “¿Acaso porque algún crítico ha dicho que Neruda no existiría sin Huidobro? Pero Huidobro no se enojaría si le dijeran que él no habría podido existir sin Rimbaud o sin Apollinaire" (p. 30). De este modo, se homologa en un mismo nivel a Huidobro con dos poetas franceses ya consagrados internacionalmente al haber propuesto una experimentación radical en la poesía. Por ende, Neruda es colocado detrás de Huidobro o, mejor dicho, en un escalón más abajo, como si se tratara de su discípulo literario. A continuación, nuevas acusaciones son enumeradas por medio del paralelismo sintáctico, procedimiento que enfatiza el carácter insistente y ridículo del discurso de los otros:

Huidobro tiene la culpa de que Neruda haya plagiado.

Huidobro tiene la culpa de que Tagore se dejara plagiar.

Huidobro tiene la culpa de que Neruda leyera a Tagore.

Huidobro tiene la culpa de que Volodia descubriera el plagio.

Ataquemos a Huidobro, calumniemos a Huidobro. (p. 30)

Por medio de la repetición léxica y sintáctica, se indica el distanciamiento irónico respecto de las voces ajenas, en especial, por la acumulación de razones insólitas y sinsentido. Finalmente, la sugerencia se hace explícita, explicando que "Los Compinches de Neruda empiezan su campaña subterránea de mentiras y de intrigas. Un día Huidobro se cansa y amanece de mal humor y se decide a hacer estallar el absceso de intrigantes, capitaneados por Tomás Lagos 
y Diego Muñoz" (p. 30). La última oración es seguida del "Primer comentario" firmado por Vicente Huidobro, donde se pregunta: "¿Es que mi presencia en el mundo es un obstáculo para la felicidad del señor Neruda y sus amigos? / Siento mucho no poderme suicidar por el momento" (p. 30). Otra vez, la ironía se entrevé en su discurso: no argumenta ni a favor ni en contra, no explica, no pide disculpas, no emplea la cortesía hacia sus colegas poetas, sino que continúa el juego de sus adversarios y dice lo que los otros están esperando escuchar.

Debajo del "Primer comentario", se transcribe "Pablo Neruda, plagiario o gran poeta", artículo publicado en el diario La Opinión y firmado por "Justiciero". Aquí el autor anónimo pone en evidencia que mientras le detectan plagios a Neruda, García Lorca reconoce a Huidobro como el mejor poeta americano después de Rubén Darío. Sin embargo, tal reconocimiento es desestimado: "La proclamación de García Lorca tendría valor si él lo tuviera, pero todos los poetas de primer plano que escriben en español niegan al andaluz una alta categoría, le consideran un poeta mediocre, un simple tonadillero. Así vistas las cosas, su opinión carece de importancia" (p. 30). La superioridad de la obra huidobriana sobre la nerudiana es justificada por medio de un juicio que realiza un intelectual, lo que demuestra que es él quien puede adjudicar valor a la obra de arte y no la obra en sí misma. De igual modo, la descalificación que hacen los poetas españoles de la obra de Lorca, y reproducida en esta revista, evidencia los agentes y sistemas de agentes que operan en la construcción del campo intelectual. Las (des)acreditaciones elaboradas entre escritores determinan qué autor o qué obra se posiciona dentro de la legitimidad artística. ${ }^{10}$ Por medio de una estrategia similar, cita a uno de los “jóvenes poetas de más valer": "A mí no me interesa ser el primer poeta después de Darío, a mí me interesa ser el primer poeta después de Huidobro" (p. 31). Como el argumento de Lorca no tiene mérito, se inserta una opinión aparentemente legítima pero no se especifica quién es el que la proclama. Por tanto, el argumento pierde efectividad aunque puede observarse la estrategia de introducir citas de autoridad que reconozcan el prestigio del autor y su posición jerárquica frente al resto de los poetas nacionales y latinoamericanos. Huidobro, consciente de que ser escritor depende de la recepción del público y de los intelectuales "porque el reconocimiento de esta verdad está encerrado en un proyecto que es siempre proyecto de ser reconocido" (Bourdieu, 2002, p. 19), construye a través de sus revistas una figura de autor más prestigiosa que Neruda por ser aclamado por otros intelectuales como un poeta fundador de una nueva generación artística.

\section{La competencia por la legitimidad cultural: Huidobro contra Lagos, Muñozy Neruda}

"Reventando el absceso" — título que anticipa el tono hiperbólico, grotesco y desenfrenado del artículo-, firmado por Vicente Huidobro, emplea una desca- 
lificación insistente contra el poeta chileno Tomás Lagos (1903-1975), a quien agravia por haberle "lanzado calumnias y sus habituales porquerías" (p. 31). En lugar de debatir aspectos poéticos, desacredita al otro por medio de la caricatura y la animalización: "A los reptiles les duele el desprecio de los hombres y tratan de vengarse como pueden" (p. 32). Además de acusarlo de irracionalidad, introduce un insulto de manera directa al aseverar "Ya me habían dicho que es Ud. chismoso e intrigante como cortesana vieja. Desgraciado" (p. 32). No hay, pues, un afán por respetar ningún tipo de decoro. Tal retrato de Lagos empeora aún más en "Le considero a Ud. un perfecto idiota, un cretino absoluto y nadie más cobarde que Ud." (p. 32), pues emplea una enumeración de insultos para, finalmente, anunciar por medio del superlativo el grado máximo de su ineptitud e inferioridad. La repetición de la estructura sintáctica que comienza por medio de "Es Ud." seguido de un sintagma nominal que desacredita la figura de Lagos da cuenta de la acumulación de argumentos en contra del adversario, la sobrecarga de justificaciones que son, en realidad, una catarata de agravios que socavan la jerarquía literaria del otro. El director de esta revista hasta se posiciona en un nivel de superioridad al ofrecerle "dar una leccioncita" a él y a sus colegas: "Y si alguno de sus amigos quiere otra, dígales que les reservo su turno" (p. 32). Por otro lado, mientras el resto de los poetas se enfadan o, mejor dicho, se indignan con "furia uterina" por las acusaciones de plagio, Huidobro se toma la cuestión como si se tratara de un mero divertimento: "Estoy con ganas de divertirme un poco en estos días de Pascuas" (p. 32), restándole importancia a la disputa y, por ende, a los argumentos de sus contrincantes.

Los procedimientos estéticos mencionados están al servicio de ridiculizar la figura de su adversario y enaltecer la propia. Al igual que hace con Lagos, Huidobro ataca a Diego Muñoz al caricaturizarlo como un "literatoide policiaco autor de un librito” (p. 32), para inmediatamente después, destacar su propia producción literaria: "en el cual lo único pasable es el título 'De repente' título robado de un libro de poemas mío, publicado en París en 1925" (p. 32). ${ }^{11}$ Se beneficia de este debate sobre plagios para problematizar quién es el nuevo poeta chileno, que lejos está, según Huidobro, de ser Lagos: "Este señor se las quiere dar de escritor nuevo (...) y sólo ha sido capaz de ser un policía modelo” (p. 32). Se puede observar, una vez más, la rivalidad entre los escritores por alcanzar la legitimidad cultural. El escrito de Huidobro afirma: "Es necesario que todo el mundo sepa que en Chile existe un escritor que da la mano, que saluda, que es al mismo tiempo policía. Esto sólo puede pasar en Chile. Pobre Chile” (p. 32). Mediante esta cita se pone en juego la representación que la sociedad chilena hace del artista a la hora de valorar una obra literaria. Huidobro, para persuadir al público lector, debe enfrentar la interpretación social de la obra del adversario así como la propia. Además, estos dos textos no son una descalificación contra Lagos y Muñoz sino contra Pablo Neruda, puesto que en "El otro" culmina diciendo "Y este señor es un gran admirador de Neruda" (p. 32). Homologa a 
estos tres poetas y los ubica en una misma posición ética y estética, de modo que cada descalificación hacia ellos también se expande en contra de Neruda.

"Precisemos" es el siguiente apartado que enumera una serie de argumentos mediante los cuales Huidobro se defiende ante las acusaciones de Neruda y los escritores adeptos. El título genera expectativas al proponer un texto que promete ser claro y conciso. En rigor, comienza de ese modo, por medio de números que estructuran la información pero, en forma gradual, se irá disgregando su plan de escritura al incluir nuevos temas y acusaciones que se apartan de la argumentación principal. Nuevamente, se recurre a una escritura desenfrenada a fin de difamar la figura de Neruda mediante comparaciones como "esta vieja dulzona", "la pobrecita" o "este triste personaje" (p. 33), y denigrar su obra poética, a la cual considera como "poesía de mama-abuela [sic] hecha especialmente para los Lagos, los Muñoz y algunas otras cocineras” (p. 32).

De este modo, construye dos genealogías de escritores chilenos: por un lado, una literatura liderada por Neruda, que es anticuada, vulgar, en tanto se desarrolla "en su ambiente de putillas chismosas" (p. 33), "ambiente de viejas intrigantes y de literatoides borrachos que ellos adoran y que ellos creen parte esencial de la vida artística" (p. 33); por otro lado, la impulsada por Huidobro, quien se considera a sí mismo un alentador de los jóvenes escritores —-Es falso que yo ignore a los jóvenes, nadie les alienta más y nada se interesa más sinceramente por ellos" (p. 33) - y un promotor de un arte al servicio de la transformación social, tal como afirma en el artículo 6: "Hoy día considero que no tengo otro deber que servir a lo único que puedo servir sin avergonzarme de mí: la revolución social" (p. 33). Por ende, el "yoísmo" propio de la estética precedente de Huidobro y que persiste en estas revistas -en frases como "Ignoro por qué razón el señor Neruda cada vez que puede trata de socavarme hipócritamente. Se diría que soy su dolor de cabeza. Y yo que me preocupo tan poco de él" (p. 33) - , por momentos se fisura al proclamar la necesidad de correrse hacia una figura de escritor cerca del "proletariado", al "estudiar sus problemas, sus luchas, sus reivindicaciones y aprender humildemente a servir la gran causa de la revolución o sea de la justicia" (p. 33). En "Confieso todas mis taras burguesas, pero tengo la esperanza de irlas corrigiendo día a día”, concede la necesidad de distanciarse de su procedencia de clase y, así, aprender de las capas sociales oprimidas que lo obligan a reconstruir su propia imagen de autor y su propia escritura.

Frente a estas acusaciones de Huidobro, Pablo Neruda le responde en el extenso y violento poema "Aquí estoy", difundido en 1935 de forma anónima y, luego, confirmada su autoría en una conferencia de 1936 llevada a cabo en la Universidad de Chile. Allí, alude a la revista Ombligo de Huidobro, donde afirma con vehemencia: 
Permitidme cagarme en vuestras cosas y en vuestras abuelas, / Y en las revistillas de jóvenes ombligos / En que derretís las últimas chispas que os salen del culo. (...) De nada vale vuestro nombre de pila traducido al francés, / Como convinche al juda cursi, / De nada venir de Talca dispuestos a ser genios, / Os mato / Os mato con espumas y sacrificios / Os meo / Envidiosos, ladrones / HIJOS DEL HIJO DE LA SUEGRA DE LA PUTA. (1975 [1935], s/d)

A través de un discurso escatológico cargado de odio e injurias, se puede vislumbrar la concepción de literatura promovida por Neruda y su estrecha relación con la política. Según su lectura, la poesía de Huidobro padece europeísmo al reproducir o trasplantar las estéticas y cosmovisiones francesas en lugar de observar e intervenir en la realidad circundante. Denuncia su falta de compromiso social cuando señala que mientras los poetas envían anónimos y fabrican plagios, "el mundo se surte de llantos a cada lado, / Y los trabajadores y los alcaldes crujen de sangre" (Neruda, 1936, s/d). Ante estas imputaciones de Neruda, que exponen la predilección de Huidobro por los juegos humorísticos y las rencillas literarias en desmedro de la denuncia política y la transformación, el director de la revista Vital, como vimos, debe aclarar su compromiso con la causa de los trabajadores y su voluntad por reconstruir su literatura, ahora más comprometida en lo referido a la revolución social.

\section{Conclusiones}

A lo largo del artículo hemos examinado que las revistas Ombligo y Vital entablan polémicas contra los defensores de una prensa, una crítica literaria y una poesía "conservadoras", arraigadas en concepciones políticas y artísticas "anticuadas", según la caracterización de los miembros colaboradores de estas publicaciones periódicas. Para distanciarse de dicho posicionamiento ideológico y para denunciar el avance del fascismo o la decadencia de una literatura creada por "vírgenes dulzonas", ridiculizan los discursos de la otredad a través de la ironía. Por ende, las reglas de la retórica clásica respecto de la forma y el tratamiento del rival son sustituidas por una variedad de juegos humorísticos, propios de las revistas vanguardistas, a fin de impulsar otra poesía, en especial, el creacionismo fundado por su director. No obstante, Vicente Huidobro declara la intención de horadar la representación social que la crítica, los poetas y el público lector han construido sobre su obra y su figura de autor, caracterizada por encasillarlo en una vanguardia artística, elitista, desatendida de las luchas sociales, por su proveniencia social aristocrática y por su credo estético independiente del mundo exterior. El renombre del escritor, es decir, "la representación que la sociedad se hace del valor y de la verdad de la obra de un escritor o de un artista" (Bourdieu, 2002, p. 18), no es ignorado por Huidobro, por lo que decide reconstruir ese personaje que la sociedad y el campo intelectual hispa- 
noamericano le inviste a través de una redefinición de su proyecto creador, cada vez más cercano al proletariado y en pugna con las instituciones dominantes del arte y de la política.

Además de enfrentarse a la definición social de su obra, las estrategias desplegadas en Ombligo y Vital responden a una búsqueda de reconocimiento por sus alter ego, es decir, "el otro intelectual, contemporáneo o futuro, capaz de seguir, en su creación o comprensión de las obras, la misma vocación propiamente intelectual que define al intelectual autónomo, sin reconocer más legitimidad que la intelectual" (Bourdieu, 2002, p. 16). Las polémicas desarrolladas en estas publicaciones, sobre todo la disputa entre Neruda y Huidobro, entre una poesía impura y una creacionista, ilustran la disputa por la legitimidad cultural. Frente a esta pugna por ocupar una posición privilegiada en el campo literario, Huidobro comienza a trastocar su concepción del arte y sus relaciones con la política, lo que lo llevará a poner en tensión sus propias formas de escribir. Es decir, a partir de las variaciones del discurso polémico y sus destinatarios, las formas y el objeto de sus críticas y denuncias, estas revistas presentan una continuidad respecto del creacionismo aunque, al mismo tiempo, se pueden observar atenuaciones o distanciamientos, en beneficio de una vertiente más comprometida con los problemas de la actualidad política local y europea.

\section{Notas}

1 Profesora y Licenciada en Letras, becaria de investigación y estudiante de la Maestría en Letras Hispánicas en la Universidad Nacional de Mar del Plata, Argentina. Este artículo forma parte de una investigación iniciada en 2016 en el marco de una beca otorgada por el Consejo Interuniversitario Nacional, cuyo principal resultado lo constituye nuestra tesina de licenciatura, dirigida por el Dr. Francisco Aiello y recientemente defendida en la UNMdP. Actualmente estudia la dramaturgia del cubano José Triana desarrollada entre 19601965, trabajo que se inserta en una beca de investigación de la UNMdP.

2 Si bien la obra de Vicente Huidobro ha merecido una vasta bibliografía, ciertas publicaciones, a causa de su dispersión o carácter efímero, han sido obliteradas o apenas aludidas por los estudios académicos. Tal es el caso de las revistas Ombligo (1934), Vital (1934, 1935), Total (1936, 1938) y Actual (1944). Gracias a la reunión de estos materiales en un volumen de la editorial Ocholibros y la Fundación Vicente Huidobro, ha sido posible emprender el examen de este corpus en nuestra tesina de licenciatura. En dicho estudio, se analizan las cuatro publicaciones como espacios discursivos que integran no sólo la tendencia artística sino también la vertiente política de las vanguardias latinoamericanas y del autor chileno en especial.

3 Según Eliseo Verón, el prodestinatario sería aquel que comparte los valores con el enunciador, por lo que es incluido dentro del "nosotros". En cambio, el contradestinatario es excluido por tener creencias inversas, de modo que le corresponde lo relacionado con la función polémica del discurso. Por otro lado, considera al paradestinario a aquel que está "fuera del juego" y, por ende, es el que debe ser persuadido (Cfr. Verón, 1987). 
4 De aquí en adelante, las referencias bibliográficas de la obra Revistas Ombligo / Vital / Total / Actual de la editorial OchoLibros y Fundación Vicente Huidobro serán consignadas solamente con el número de página.

$5 \mathrm{El}$ rechazo a Marinetti y a su movimiento ya había sido expresado por Huidobro en el texto programático "El futurismo": "Todo eso de cantar la temeridad, el valor, la audacia, el paso gimnástico, la bofetada, es demasiado viejo. Lea si no, el señor Marinetti, La Odisea y La Ilíada, La Eneida o cualquiera de las Odas de Píndaro a los triunfadores en los juegos olímpicos y encontrará allí toda su gran novedad" (Huidobro, 1976, p. 699). El poeta chileno acusa a este ismo de repetir formas anticuadas y poco innovadoras a pesar de los temas vinculados con avances técnicos, por lo que la opone a su poesía creadora de imágenes inéditas, no subordinada al referente.

6 Esta alusión a "la cuadratura del círculo" nos obliga a trazar un diálogo intertextual con la imagen creacionista horizon carré, presente en su poemario homónimo de 1917 y resignificada en sus obras poéticas posteriores. Ya en el libro publicado en Francia y escrito en francés, quizá para alejarse del lenguaje que se habla y superar la lengua nacional —como afirma un verso de Altazor: "se debe escribir en una lengua que no sea materna" (Huidobro, 2012a, p. 8) - , reúne poemas que contienen yuxtaposiciones de figuras distintas e incluso antinómicas, procedimiento heredado de la técnica cubista. "Horizonte cuadrado" sintetiza los principios básicos del creacionismo: "humanizar las cosas", "lo vago se hace preciso", "lo abstracto se hace concreto y lo concreto abstracto" y "lo que es demasiado poético como para ser creado se convierte en una creación si cambiamos su valor usual" (Huidobro, 2012b, p. 291), rasgos enumerados por Huidobro en su manifiesto "El creacionismo" (1925). La imagen creacionista, por ende, conjuga categorías opuestas creando imágenes variadas y distantes entre sí, "cuya unión, rebosante de plasticidad, sugiere inéditas y sorprendentes relaciones entre campos semánticos distintos” (Morelli, 2012, p. 18).

7 Por un lado, enumera a tres dirigentes políticos representantes del conservadurismo chileno: Rafael Luis Gumucio, militante del Partido Conservador y senador de la República para los años 30; Ricardo Boizard, escritor, periodista y político chileno del Partido Conservador (1920-1935) y más adelante de la Falange Nacional (1935-1957); y Arturo Olavarría, político chileno, militante radical aunque hacia 1940 funda la Acción Política Anticomunista. En grupo antagónico, ubica a André Gidé, Henri Barbusse, Einstein y Stalin por su adscripción política al comunismo o a otros partidos de izquierda.

8 Estas premisas del creacionismo se vinculan con la exaltación por parte de Huidobro de la hiperconciencia y la razón, en desmedro de la escritura automática del surrealismo. Como sostiene en "Manifiesto de manifiestos" (1925, París), durante la composición y el engranaje del poema el poeta debe tener un papel activo: "La poesía ha de ser creada por el poeta, con toda la fuerza de sus sentidos más despiertos que nunca" (2012b, p. 288). Repugna escribir como un médium, automáticamente, por ser demasiado "banal” y "fácil" en comparación con la poesía que surge de la hiperconciencia. Esto ya había sido proclamado en otras conferencias (Buenos Aires, Madrid, Berlín, Estocolmo, París), donde se opone al sueño buscado por los surrealistas, asociado a un estado de "debilidad mental". La diferencia radica en que la hiperconciencia, también denominada "delirio poético" (2012b, p. 289), sigue estando controlada por la razón, puesta en el mismo plano de la imaginación, y es una cualidad exclusiva de los poetas (Cfr. Barón, 1981).

9 Pablo Neruda y Vicente Huidobro ocupan posiciones enfrentadas dentro de la izquierda chilena. Mientras que el primero representa un "antifascismo guerrero", Huidobro sirve activamente en un "comunismo más militante" (De Costa, 1978, p. 381) desde los años 20. En efecto, esto provoca la bifurcación de los intelectuales chilenos en dos asociaciones: la Alianza de Intelectuales de Chile, liderada por Neruda, y el Sindicato Profesional de 
Trabajadores Intelectuales de Chile, cuyos miembros más destacados son Huidobro y de Rokha. Tal pugna lleva también a la creación de dos delegaciones chilenas en colaboración con el bando republicano durante la Guerra Civil Española, a tal punto que la Association des Écrivains pour la Défense de la Culture escribe la misma carta a Neruda y Huidobro en 1937 para pedirles que cesen la querella en pos de priorizar el compromiso con la causa republicana (véase De costa, 1978).

10 Pierre Bourdieu, en su estudio sobre el campo de poder y campo intelectual, sostiene que el valor de la obra de arte se obtiene del "conjunto de los juicios potenciales sobre la obra, que el conjunto de los miembros del universo intelectual podrá o podría formular al referirse, en todos los casos, a la representación social de la obra como integración de juicios singulares sobre la obra" (2002, p. 30). Por ende, el autor se define a través de las relaciones sociales que mantiene con el conjunto de agentes que constituyen el campo intelectual en un momento dado del tiempo: otros artistas, críticos, editores, comerciantes o periodistas, todos ellos mediadores entre el artista y el público.

11 Huidobro se refiere a la novela corta De repente del escritor y periodista chileno Diego Muñoz (1903-1990) compuesta durante los años 20 y publicada en 1933, que narra la vida de personajes de la bohemia y la marginalidad de Santiago (véase Muñoz, 1964).

\section{Referencias bibliográficas}

Bajtín, M. (1982). Estética de la creación verbal. México: Siglo XXI.

Barón, E. (1981). André Breton y Vicente Huidobro: Las poéticas surrealista y creacionista. Anales de Literatura Hispanoamericana, IX (10), 67-83. https://revistas.ucm.es/index.php/ALHI/article/view/ALHI8181110067A/24433

Bourdieu, P. (2002). Campo de poder, campo intelectual. Buenos Aires: Montressor.

Costa, R. d. (1978). Postdata: Neruda sobre Huidobro. En En pos de Huidobro. Siete ensayos de aproximación. Santiago: Editorial Universitaria. pp. 379-386.

Ducrot, O. (2004). Sentido y argumentación. En E. Arnoux y M. M. García Negroni (eds.) Homenaje a Oswald Ducrot. Buenos Aires: Eudeba. 359-370.

García Negroni, M. M. (2016). Discurso político, contradestinación indirecta y puntos de vista evidenciales. La multidestinación en el discurso político revisitada. Revista Aled, 16 (1), pp. 37-59. https://dialnet.unirioja.es/servlet/articulo?codigo $=5958979$

Huidobro, V. (1976). El futurismo. En Obras completas. Tomo I. Santiago: Editorial Andrés Bello. pp. 698-701.

Huidobro, V. (2012a). Altazor o el viaje en paracaídas. Santiago de Chile: Ocho Libros Editores y Fundación Vicente Huidobro.

Huidobro, V. (2012b). Poesía y creación. Madrid: Banco Santander Río.

Huidobro, V. (2012c). Revistas: Ombligo / Vital / Total / Actual (Prólogo de Kurt Folch). Santiago: Ocho Libros Editores y Fundación Vicente Huidobro.

Jitrik, N. (1995). Las dos tentaciones de la vanguardia. En Pizarro, Ana (coordinadora). América Latina: Palavra, Literatura e Cultura. Vol. 3. Vanguarda e Modernidade. São Paulo: Memoriail; Campinas: UNICAMP. 57-74. 
López Eire, A. (2000). Retórica y política. En Cortés Gabaudán, F., Hinojo, G. y López Eire, A. (Eds.). Retórica, Politica e Ideologia. Desde la Antigüedad hasta nuestros dias. Salamanca: Logo. pp. 99-139.

Molina, C. A. (1995). Ilustre seductor y camorrista. En Valcárcel, E. (Ed.). Huidobro. Homenaje. La Coruña: Universidad. pp. 137-141.

Morelli, G. (2007). Neruda y la generación del 27: la polémica con Huidobro. En Roses, J. (Ed.) Pablo Neruda en el corazón de España. Actas del Congreso Internacional. Córdoba: Diputación. pp. 105-122.

Morelli, G. (2012). Vicente Huidobro, demiurgo y cantor del verbo nuevo. En Huidobro, V. Poesía y creación. Madrid: Banco Santander Río. VIII-LXV.

Neruda, P. (1975). Obras completas. Buenos Aires: Losada.

Ostrov, A. (2006). Altazor de Vicente Huidobro: la realidad en el lenguaje. En Graña, M.C. (Ed.). La suma que es el todo y que no cesa. El poema largo en la modernidad hispanoamericana. Rosario: Beatriz Viterbo. pp. 39-58.

Perelman, C. y Olbrechts-Tyteca, L. (1989). Tratado de la argumentación. La nueva retórica (Traducción española de Julia Sevilla Muño). Madrid: Gredos.

Poggioli, R. (1964). Teoría del Arte de Vanguardia. Madrid: Revista de Occidente.

Rodríguez Gutiérrez, M. (2008). Dos planetas poéticos: Huidobro versus Neruda y viceversa. Anales de Literatura Chilena, 9 (9), pp. 185-203.

Rojas, W. (1999). Sobre algunos acercamientos y prevenciones a la obra poética de Vicente Huidobro en Lengua Francesa. En Huidobro, V. Obras poéticas en francés (Edición bilingüe). Traducción, introducción y notas de Waldo Rojas. Santiago de Chile: Editorial Universitaria. pp. 9-38.

Sanhueza, L. (compilación y prólogo) (2004). El Bacalao. Diatribas antinerudianas y otros textos. Santiago: Ediciones B.

Verón, E. (1987). La palabra adversativa. Observaciones sobre la enunciación política. En El Discurso Político. Buenos Aires: Hachette. pp. 13-26.

Williamson, E. (2013). Historia de América Latina. México: Fondo de Cultura Económica.

Zerán, F. (2011). La guerrilla literaria: Pablo de Rokha, Vicente Huidobro, Pablo Neruda. Santiago: Debolsillo. 